\title{
Bacteria alone establish the chemical basis of the wood-fall chemosynthetic ecosystem in the deep-sea
}

\author{
Dimitri Kalenitchenko ${ }^{1}$, Nadine Le Bris ${ }^{1}$, Laetitia Dadaglio ${ }^{1}$, Erwan Peru ${ }^{1}$, Arnaud Besserer ${ }^{2}$ \\ and Pierre E Galand ${ }^{1}$ \\ ${ }^{1}$ Sorbonne Universités, UPMC Univ Paris 06, CNRS, Laboratoire d'Ecogéochimie des Environnements \\ Benthiques (LECOB), Observatoire Océanologique, Banyuls sur Mer, France and ${ }^{2}$ Université de Lorraine, \\ Laboratoire d'étude du matériau bois (LERMAB), Campus bois, Epinal, France
}

\begin{abstract}
Wood-fall ecosystems host chemosynthetic bacteria that use hydrogen sulfide as an electron donor. The production of hydrogen sulfide from decaying wood in the deep-sea has long been suspected to rely on the activity of wood-boring bivalves, Xylophaga spp. However, recent mesocosm experiments have shown hydrogen sulfide production in the absence of wood borers. Here, we combined in situ chemical measurements, amplicon sequencing and metagenomics to test whether the presence of Xylophaga spp.-affected hydrogen sulfide production and wood microbial community assemblages. During a short-term experiment conducted in a deep-sea canyon, we found that wood-fall microbial communities could produce hydrogen sulfide in the absence of Xylophaga spp. The presence of wood borers had a strong impact on the microbial community composition on the wood surface but not in the wood centre, where communities were observed to be homogeneous among different samples. When wood borers were excluded, the wood centre community did not have the genetic potential to degrade cellulose or hemicellulose but could use shorter carbohydrates such as sucrose. We conclude that wood centre communities produce fermentation products that can be used by the sulfate-reducing bacteria detected near the wood surface. We thus demonstrate that microorganisms alone could establish the chemical basis essential for the recruitment of chemolithotrophic organisms in deep-sea wood falls.
\end{abstract}

The ISME Journal (2018) 12, 367-379; doi:10.1038/ismej.2017.163; published online 6 October 2017

\section{Introduction}

Wood falls are described as one of the four chemosynthetic deep-sea ecosystems that harbour diverse and specialized macrofauna (Kiel et al., 2009; Bernardino et al., 2010), meiofauna (Cuvelier et al., 2014) and microorganism communities (Bienhold et al., 2013; Fagervold et al., 2013; Bessette et al., 2014). The inclusion of wood falls among chemoautotrophic ecosystems refers to the presence of animal species, which are phylogenetically related to hydrothermal vents and cold seep lineages (Dando et al., 1992; Distel et al., 2000; Lorion et al., 2009) and host chemoautotrophic symbiotic bacteria. These bacterial symbionts are sulfur oxidizers that may use the hydrogen sulfide released during wood degradation (Duperron et al., 2008). The origin of this reduced compound is different for wood than for hydrothermal vents,

Correspondence: D Kalenitchenko, Sorbonne Universités, UPMC Univ Paris 06, CNRS, Laboratoire D'Ecogéochimie des Environnements Benthiques (LECOB), Observatoire Océanologique, Banyuls sur Mer, France.

E-mail: dimitri.kalenitchenko@gmail.com

Received 17 February 2017; revised 29 June 2017; accepted 24

August 2017; published online 6 October 2017 where sulfides originate from abiotic reactions at high temperatures and pressures (German and Damm, 2006), or for cold seeps, where it is a byproduct of the biotic anaerobic oxidation of methane formed from the degradation of fossil organic matter trapped in sediments (Levin, 2005). By contrast, in organic falls, like dead whales or wood logs that reach the seafloor, reduced compounds directly originate from the biological degradation of the substrate itself. In the well-studied whale fall systems, the chemoautotrophic community relies on the heterotrophic activity of microorganisms using the lipid content of bone (Deming et al., 1997; Smith and Baco, 2003). These microorganisms were identified as sulfate-reducing bacteria that used sulfate as a terminal electron acceptor and produced hydrogen sulfide while using small organic compounds, such as acetate as a carbon source (Treude et al., 2009; Shapiro and Spangler, 2009). By contrast, wood is mostly made of cellulose and lignin, two highly refractory compounds (Gessner, 2005). Their degradation in anaerobic environments, such as sunken woods, is performed by complex communities of microorganisms, including fungi and bacteria (Ljungdahl and Eriksson, 1985; Leschine, 1995). 
Sunken wood on the seafloor harbour highly diverse bacterial communities that include potential sugar degrading, fermenting and sulfate-reducing bacteria but few potential cellulose degraders (Palacios et al., 2009; Bienhold et al., 2013; Fagervold et al., 2013; Ristova et al., 2017). In aquaria, these diverse communities showed clear ecological succession during a 1-year incubation, and the presence of $16 \mathrm{~S}$ rRNA gene sequences from sulfate reducers was related to hydrogen sulfide accumulations first detected after 1 month of immersion (Yücel et al., 2013; Kalenitchenko et al., 2015). Over this short time-scale, wood sulfate reducers could use small organic compounds derived from polysaccharide fermentation. The major polysaccharide present in wood is cellulose but plants also use sucrose to transport the carbon fixed in leaves or needles through the phloem (Büttner and Sauer, 2000; Lemoine et al., 2013). Sucrose is used by many heterotrophic bacteria as a carbon source (Reid and Abratt, 2005). Even if present as only a small part of the carbohydrate pool, sucrose may represent a less-refractory carbon source than cellulose for opportunistic bacteria.

Cellulose degradation in sunken wood is hypothesized to be done mostly after wood ingestion by macrofaunal borers such as Xylophaga spp. through enzymes produced by the microbial symbionts in the gills (Distel and Roberts, 1997; Voight, 2015). Furthermore, it is thought that without the initial degradation of the wood by wood borers, which hydrolyze cellulose in association with their bacterial symbionts (Distel and Roberts, 1997), sulfidic niches might not develop (Bienhold et al., 2013). Xylophaga spp. are hypothesized to create niches for bacteria through the development of anoxic zones, which originate from the accumulation of faeces rich in cellulose degradation breakdown products and the production of mucus (Purchon, 1941; Bienhold et al., 2013). It was recently shown that Xylophaga spp. faeces host-specific microbial communities (Fagervold et al., 2014), which supports the idea that Xylophaga spp. have an important role in the sunken wood ecosystem. However, recent results obtained from aquaria experiments suggest a different picture for the early stages of wood colonization. Sulfate-reducing bacteria quickly occupied the wood matrix, and hydrogen sulfide reached millimolar concentrations ( $>1 \mathrm{~mm}\left[\mathrm{H}_{2} \mathrm{~S}\right]$ ) before any wood borers were detected (Yücel et al., 2013; Kalenitchenko et al., 2015).

In this study, we first tested whether the presence of wood microbes alone, without wood-boring bivalves, could lead to the production of hydrogen sulfide and provide support for a chemosynthetic ecosystem in the natural conditions of a deep-sea environment. Second, we tested whether the presence of borers modifies microbial community assembly and if it could favour sulfide availability for wood chemoautotrophs. We designed an exclusion experiment that was deployed for 2 months in a submarine canyon known to harbour Xylophaga spp. We used pine wood to compare our results with previous studies (Yücel et al., 2013; Fagervold et al., 2014; Kalenitchenko et al., 2015) and protected half of our replicate samples with a mesh to prevent Xylophaga spp. larval colonization. We characterized the microbial community by sequencing a partial fragment of the bacterial $16 \mathrm{~S}$ rRNA gene on an Illumina MiSeq system and by constructing shotgun metagenomes to reveal the genetic potential of the community. Hydrogen sulfide concentrations were measured continuously in situ and used as a marker for sulfate-reducing bacterial activity.

\section{Materials and methods}

\section{Experimental design}

Wood samples were cut from one branch of a 30-year-old pine tree (Pinus pinea) from the Banyuls-sur-Mer 'Biodiversarium' botanical garden. Six pieces of wood logs $(10 \mathrm{~cm}$ in length and $14 \mathrm{~cm}$ in diameter) were placed in plastic cages $(15 \times 18 \mathrm{~cm})$. Cages were made of a rigid plastic mesh with a $13 \mathrm{~mm}$ by $13 \mathrm{~mm}$ grid. Three cages were randomly selected and covered with a $50 \mu \mathrm{m}$ mesh to prevent colonization by wood borer larvae (Culliney and Turner, 1976). Three additional wood-containing cages were left unprotected. Sulfide potentiometric electrodes were inserted $25 \mathrm{~mm}$ into the wood through $2 \mathrm{~mm}$ diameter holes drilled into one mesh-covered and one unprotected piece of wood. The hole diameter was minimized to avoid trapping water and sealed with Teflon tape. The pieces of wood were attached to an experimental platform and deployed at a depth of $520 \mathrm{~m}$ in the Lacaze-Duthiers submarine canyon in the Gulf of Lion (NW Mediterranean Sea), $25 \mathrm{~km}$ away from the shore $\left(42^{\circ} 32^{\prime} 26^{\prime \prime} \mathrm{N}, 03^{\circ} 25^{\prime} 9^{\prime \prime} \mathrm{E}\right)$ on the 27 th of April 2013 (Supplementary Figure 1) at a sea temperature of $14^{\circ} \mathrm{C}$. The platform (with cages) was recovered 85 days later (Supplementary Figure 2). Both operations were performed with a remotely operated underwater vehicle Super-Achille operated from the R/V Minibex (COMEX SA) as part of a larger integrated programme dedicated to the submarine canyon ecosystem.

\section{Wood sampling and DNA extraction}

Wood samples were obtained by extracting wood cores with a $4.35 \mathrm{~mm}$-diameter increment borer from logs recovered after 85 days of immersion. Each wood core was divided in two sub-samples: one surface sub-sample (S) covering the first centimeter of the wood, and one centre sample (C) taken from 4-5 cm deep inside the wood (Figure 1). Two wood cores were extracted from each of the three wood replicates: one sample was drilled $1 \mathrm{~cm}$ away from the bark close to the sapwood (Sa) and another $6 \mathrm{~cm}$ away from the bark in the heartwood (He) (Figure 1). Sapwood corresponds to the wood part that was 

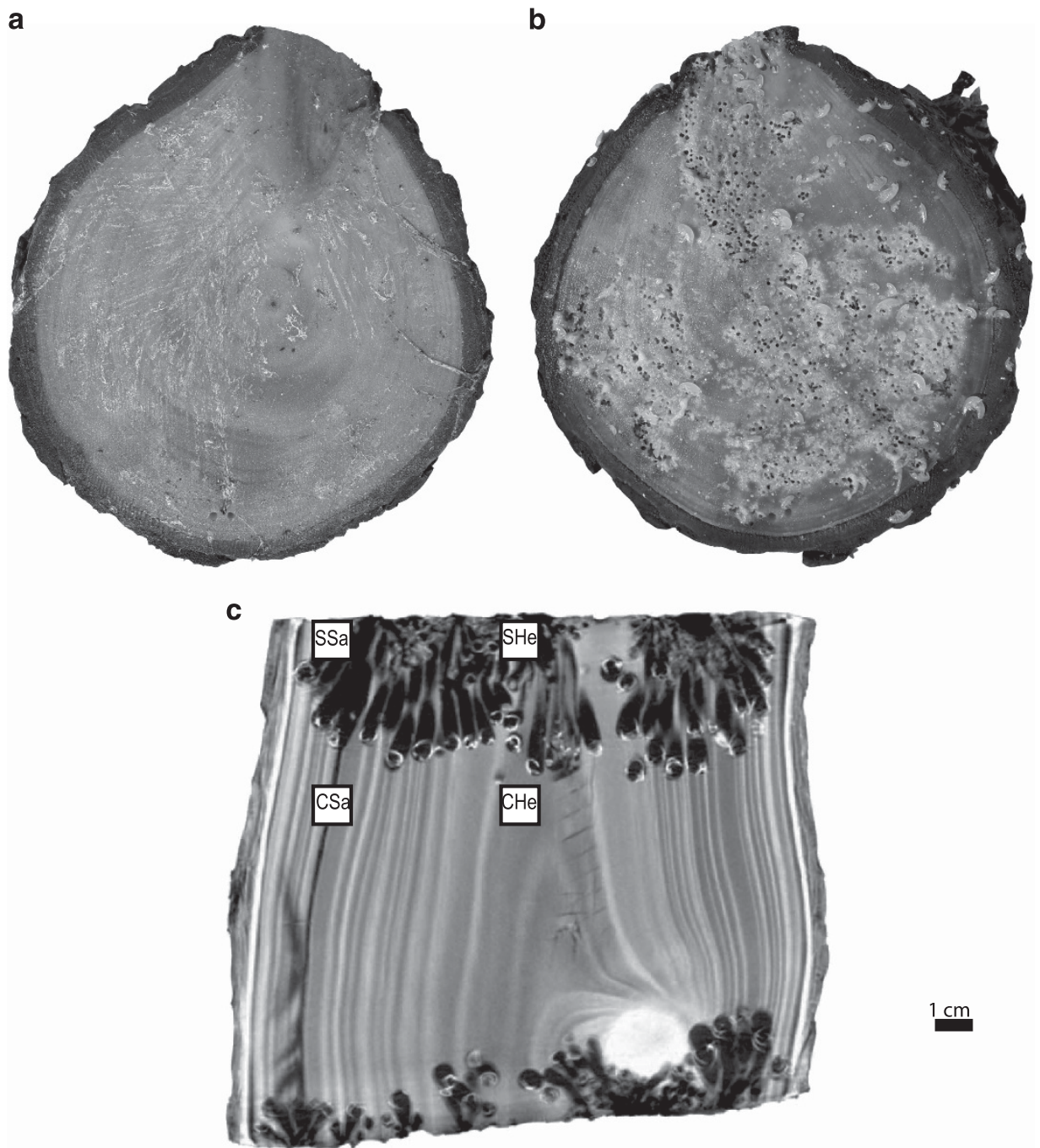

Figure 1 Picture of the intact surface of a wood sample protected by a $50 \mu \mathrm{m}$ mesh (a) and Xylophaga sp. holes on the surface of a wood sample that was not protected (b). Wood logs were immersed for 85 days in a deep-sea canyon. Longitudinal tomographic cross section of an unprotected wood showing Xylophaga sp. burrows as dark regions inside the wood (c). The different sampling locations are indicated as surface sapwood (SSa), surface heartwood (SHe), centre sapwood (CSa) and centre heartwood (CHe).

alive when the tree was cut, whereas heartwood corresponds to the dead part of the tree. For the two wood logs equipped with a hydrogen sulfide sensor, an additional core was drilled at the electrode position (sample name ends with a *).

Wood core samples $(1 \mathrm{~cm}$ long and $4.35 \mathrm{~mm}$ in diameter) were powdered using a TissueLyser (RETSCH Mixer Mill, Retsch Inc., MM301, Düsseldorf, Germany) (Palacios et al., 2009). Samples were placed in stainless steel grinding jars $(25 \mathrm{ml}$, Retsch Inc., MM400), kept in liquid nitrogen for $5 \mathrm{~min}$, and then powdered for $3 \times 1.5 \mathrm{~min}$ at $25 \mathrm{~Hz}$. DNA was extracted and purified from the wood powder with the Power Plant pro Mobio Kit (MOBIO Laboratories, Carlsbad, CA, USA) following an adapted version of the MoBio Protocol (Fagervold et al., 2013). An extra clean-up step using isopropanol was performed to remove remaining contaminants like wood tannins that are not removed by the standard protocol.
$16 S$ rRNA gene and metagenome sequencing

A partial fragment of the $16 \mathrm{~S}$ rRNA gene was amplified using bacteria-specific primers $28 \mathrm{~F}$ (5'-TTTGATCNTGGCTCAG-3') and 519R (5'-GTN TTACNGCGGCKGCTG-3') (Teske et al., 1994; Vergin et al., 1998) and then sequenced by a commercial laboratory (Research and Testing Laboratory, Lubbock, TX, USA) on an Illumina MiSeq sequencer to produce $2 \times 300$ base pair (bp)-long paired-end sequences.

For a functional description of the wood communities, six samples were selected for shotgun metagenome sequencing. Libraries were prepared with $50 \mathrm{ng}$ of DNA using the Nextera DNA sample preparation Kit (Illumina, San Diego, CA, USA) producing a library with an average insert size of $200 \mathrm{bp}$. The sequencing was performed on a Hiseq $2 \times 150 \mathrm{bp}$ Illumina sequencer by a commercial laboratory (Research and Testing Laboratory). One 
of the libraries (CSa_WM_3) was sequenced on a MiSeq $2 \times 250 \mathrm{bp}$ Illumina sequencer.

\section{Sequence data analysis}

The $16 \mathrm{~S}$ rRNA sequences were analyzed using the MiSeq standard operating procedure in Mothur (Kozich et al., 2013). In brief, sequences were merged, giving ca. $500 \mathrm{bp}$-long fragments. Sequences were then trimmed for quality, and chimeras were removed using UCHIME (Edgar et al., 2011) with a minimum score to report chimera of 0.3 , a smoothing window of 32 and a maximum number of candidate parents to consider of 2 , and the silva gold database (v123) as reference (Pruesse et al., 2007; Quast et al., 2013). Sequences were finally grouped using average linkage into oerational taxonomic units (OTUs) at a 97\% sequence similarity threshold, and taxonomy was assigned with the Wang method of the Mothur (Schloss et al., 2009) classify.seqs command using the Silva database (v.123) (Pruesse et al., 2007). The data set was resampled down to the number of sequences found in the sample with fewest sequences (SSa_WoM_2; 2425 sequences) and the singletons were removed resulting in a total of 568 OTUs. Sequences were deposited in the NCBI database under SRA accession number SRP058532 (Supplementary Table 1).

For metagenomic data, adapter and primers were first removed from the sequences, and then pairedend reads were joined with a minimum overlap setting of $8 \mathrm{bp}$ and a maximum difference of $10 \%$. Both paired and unpaired reads were retained for further analysis. Low-quality regions (phred score $\leqslant 15$ ) were trimmed using SolexaQA (Cox et al., 2010). We chose to analyze unassembled reads because the goal here was to annotate as many reads as possible rather than to reconstruct large bins. By assembling reads into bins the information contained in the read that cannot be assembled is lost. Reads that passed the quality trimming were dereplicated using a k-mer approach that identifies sequences with identical twenty character prefix, and then, artificial duplicate sequences were removed (GomezAlvarez et al., 2009). A machine learning approach known as FragGeneScan (Rho et al., 2010) identified open reading frames that were annotated using BLASTX (Camacho et al., 2009) against the M5NR (Wilke et al., 2012), KEGG (Kanehisa and Goto, 2000) and Silva (Pruesse et al., 2007) databases. Analyses were conducted with the MG-RAST pipeline (Meyer et al., 2008), and sequences are available under the accession number mgs476148, mgs476151, mgs476154, mgs476157, mgs476160 and mgs476163.

\section{Diversity and statistical analysis}

The Shannon and Simpson diversity indices were calculated on a resampled OTU table. Comparisons of alpha diversity indices were achieved in $\mathrm{R}$ with the default statistical package (2.15.13; Vienna, Austria) using non-parametric Mann-Whitney or the Kruskal-Wallis tests, followed by a multiple comparison test depending of the number of categories compared.

Beta diversity between samples was estimated with the Bray-Curtis dissimilarity index and then represented using an UPGMA (unweighted pair group method with arithmetic mean) clustering. Significant differences between sub-clusters were tested using a SIMPROF analysis (Yoshioka, 2008). We constructed heatmaps that presented the community composition at the family level, including only families that contained $>1 \%$ of the total sequence pool. Based on these heatmaps, we performed a Welch $t$-test to compare microbial community composition between samples. Analyses were conducted using the STAMP software (Parks et al., 2014), and the relationship between OTUs and samples was displayed using the CIRCOS software (Krzywinski et al., 2009).

For a sequence composition comparison between metagenomes, without the bias of annotation or assembly, we used the COMMET software (Maillet et al., 2014). COMMET conducts a direct all against all comparison of non-assembled reads and then builds a similarity matrix. Before running COMMET we did a quality filtering and trimming using the Trimmomatic software (Bolger et al., 2014) using a sliding windows of $4 \mathrm{bp}$ and a quality threshold of 20, then the first 15 bases and last 75 bases were trimmed. High-quality sequences were used as input.

We selected gene sequences belonging to bacteria based on the M5 non redundant protein database (Wilke et al., 2012) with an e-value cutoff of $1 \mathrm{e}^{-5}$, a minimum alignment coverage of $80 \%$ and a minimum length of 15 amino acids (aa). The selected sequences were then annotated with three different databases: subsystem (Overbeek et al., 2005), COG (Tatusov et al., 1997) and KEGG ontology database (Kanehisa and Goto, 2000), with an e-value cutoff of $1 \mathrm{e}^{-5}$, a minimum alignment coverage of $60 \%$ and a minimum length of 15 aa. Annotated gene abundances were normalized against the total number of bases sequenced in each sample. Then, we calculated a Bray-Curtis dissimilarity matrix between samples for the three different annotations to compare them. The subsystem annotation displayed a linear relationship against the COG annotation (Pearson, $\partial=0.99577, \quad P$-value $=1.3366 .10^{-30}$ ) (Supplementary Figure 3) and against the KEGG annotation (Pearson, $\partial=0.98827, \quad P$-value $=2.1257 .10^{-24}$ ) with a slope value of 0.8605 and 1.0083 , respectively, and an intercept close to 0 (0.0191 and -0.0459 , respectively). We therefore concluded that the choice of the database did not affect observations of inter-samples differences in annotated gene content. We chose the subsystem annotations for further analysis because it was the only one that revealed genes related to sulfur oxidation. 
Tomography data treatment and hydrogen sulfide measurement

An unprotected wood piece was scanned on a 39 Watt RX Solution Tomograph with a high tension of $0-130 \mathrm{~kW}$ and an anode current of $0-300 \mu \mathrm{A}$. The freshly recovered wood was sampled for molecular biology then frozen at $-80^{\circ} \mathrm{C}$, to kill the macrofaunal taxa, and finally dried in a controlled enclosure at $12 \%$ of relative humidity to allow an optimum visualization of the wood structures. The presence of Xylophaga spp. individuals in the wood was confirmed by the presence of previously identified Xylophaga spp. shells (Romano et al., 2014) at the bottom of the burrows.

Hydrogen sulfide was monitored inside the wood using $\mathrm{Ag} / \mathrm{Ag}_{2} \mathrm{~S}$ electrodes connected to an autonomous potentiometric sensor (NKE, SPHT), similar to the one used in a shallow water mangrove wood experiment (Laurent et al., 2013, 2009) and in other deep-sea sulfidic environments (Mullineaux et al., 2012). Calibration was performed in the laboratory, before and after deployment, to check the stability of the electrodes and allow semi-quantitative estimates. Because the associated glass electrode placed inside the wood failed, no $\mathrm{pH}$ measurement is available, preventing the quantification of sulfide concentration. Nevertheless, the signal of the $\mathrm{Ag} / \mathrm{Ag}_{2} \mathrm{~S}$ electrodes can be used to identify an increase in sulfide concentration above the detection threshold $<1 \mu \mathrm{M}$ ) and to compare the sulfide ranges between the two conditions. Here, we present raw potential data to document the variation of sulfide over time, and particularly the steep decrease in potential matching the increase of sulfide measured above the detection threshold. We also calculated raw estimates of sulfide concentrations assuming a pH of 6.5 (that is, corresponding to an equimolar concentration of $\mathrm{H}_{2} \mathrm{~S}$ and $\mathrm{HS}^{-}$in seawater), reflecting a median value in the $\mathrm{pH}$ range measured in immersed wood logs with borers, following transfer to the aquarium.

\section{Results}

Degradation of wood samples

All wood samples were recovered 85 days after being immersed at a depth of $520 \mathrm{~m}$. Samples protected with mesh (Figure 1a) did not have Xylophaga spp. holes on their surface but were covered by the remains of a white biofilm. In comparison, the wood samples without mesh had, on average, $40 \%$ of their surface covered by Xylophaga spp. holes (Figure 1b). The hole bored artificially before the experiment for insertion of the sulfide electrode was close $(0.9 \mathrm{~mm})$ to a Xylophaga spp. hole. The potential impact of Xylophaga inside the wood pieces was estimated on a longitudinal scan obtained using X-ray tomography (Figure 1c). The black areas show the Xylophaga spp. burrows, and the white circular parts at the end of the burrows are the shells of the animals. The burrows on the top of the wood were longer than the burrows at the bottom (with mean lengths of $2.6 \mathrm{~cm}$ and $1.2 \mathrm{~cm}$, respectively). After 85 days of immersion, the X-ray tomogram showed that ca. $30 \%$ of the wood volume had been bored by Xylophaga spp.

\section{Continuous measurement of sulfide concentration}

Potential values measured for both mesh-protected and unprotected wood samples remained stable during the first 21 days of immersion, indicative of the absence of sulfide. After this plateau, a steep potential decrease was measured (Figure 2a), indicating that dissolved hydrogen sulfide was starting to accumulate in the pore water surrounding the probe, at a depth of $25 \mathrm{~mm}$ inside the wood (Figure 2a). After 23-24 days of incubation, a more progressive electrical potential decrease was observed, reaching a minimum of $-0.47 \mathrm{~V}$ after 36 days in the meshprotected wood and- $0.42 \mathrm{~V}$ after 40 days in the unprotected wood, which suggests a slower accumulation of sulfide over time in the unprotected wood. In the unprotected wood, the electrode potential continued to decrease to reach a minimum of $-0.57 \mathrm{~V}$ at the end of the experiment. Unprotected wood presented a fluctuating curve with potential slight re-increases after 57 and 63 days, followed by a large re-increase after 75 days, to result in a final potential of $-0.25 \mathrm{~V}$.

Sulfide concentration estimated for a $\mathrm{pH}$ of 6.5, which provide semi-quantitative information concerning the sulfide ranges achieved in both wood samples, could be reliably calculated only after 35 days of immersion. They indicate markedly different patterns for the two sets of wood logs (Figure $2 \mathrm{~b}$ ). The estimated concentration exceeded a value of $0.1 \mu \mathrm{M}$ after 35 days in the protected wood and 5 days later in the unprotected wood. Subsequent hydrogen sulfide accumulation was, however, more pronounced when Xylophaga spp. were excluded. After 42 days, the estimated sulfide concentration exceeded $1 \mu \mathrm{M}$ in the protected wood and continued to increase up to several tens of micromoles in the following month, whereas in the presence of Xylophaga spp., the estimated concentration remained below $1 \mu \mathrm{M}$. Hydrogen sulfide estimates indicated that a concentration of several hundred micromolar may be reached after 85 days at the end of the deployment period. Wood colonized by Xylophaga spp. showed only limited and ephemeral sulfide accumulation after 42 days and between 70 and 77 days during the deployment (Figure 2b).

\section{Community alpha and beta diversity}

Alpha diversity measured as the Simpson and Shannon index showed a significant difference between the high alpha diversity measured in surface samples compared to the low diversity measured in wood centre samples (Supplementary Figure 4) (Shannon, Mann-Whitney test, $W=23$, 


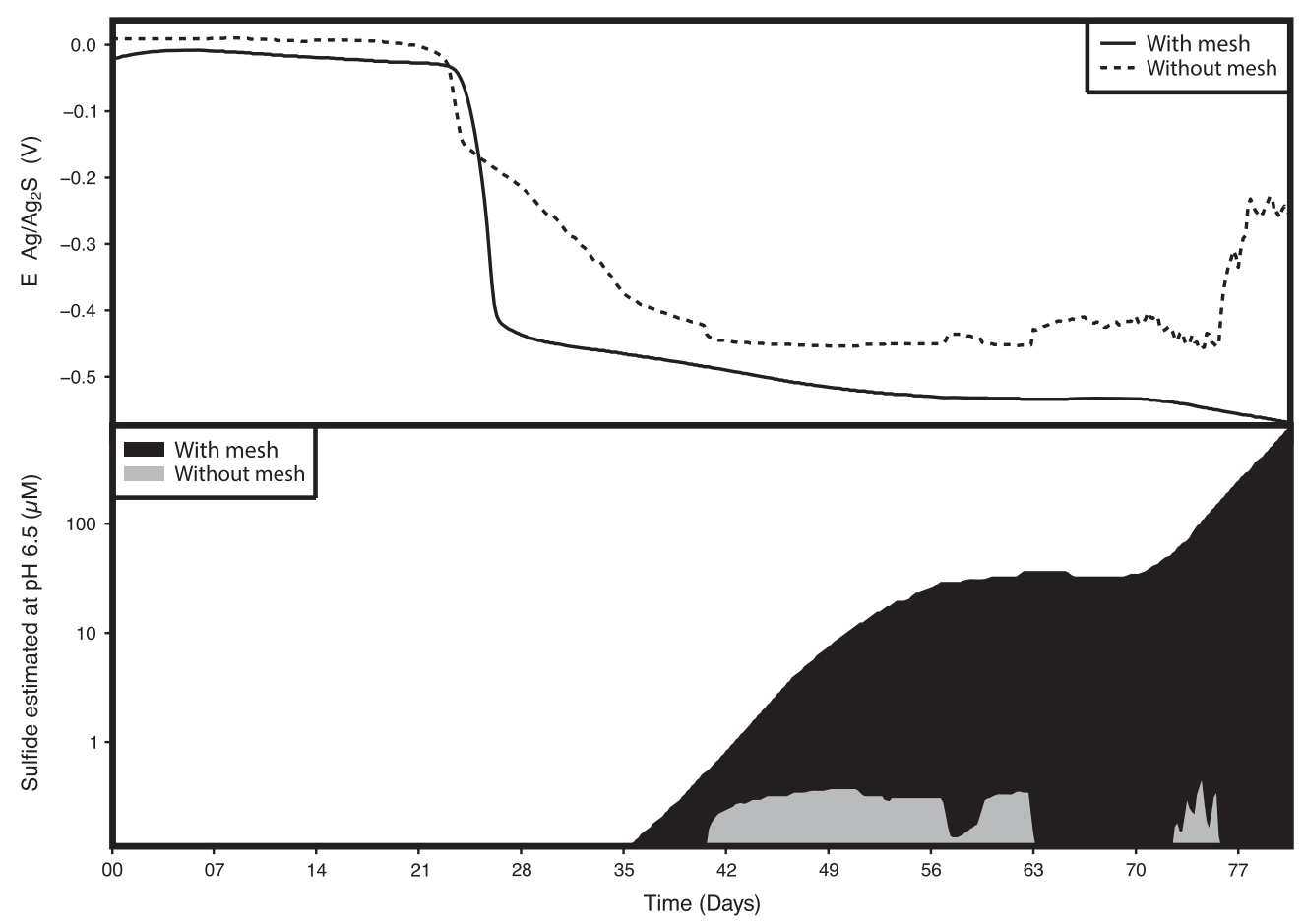

Figure 2 Raw and converted data from sulfide probe continuous measurements. The upper graph shows the probes' electrical potential signal over time $25 \mathrm{~mm}$ inside protected (continuous line) and unprotected (dashed line) wood samples. The lower graph represents the sulfide concentrations calculated for a $\mathrm{pH}=6.5$. The edge between the grey and black areas represents the sulfide concentration in the unprotected sample, and the upper limit of the black area represents the sulfide concentration in the protected samples.

$P$-value $=2.2 \mathrm{e}^{-3} ;$ Simpson, $W=19, P$-value $\left.=8.7 \mathrm{e}^{-4}\right)$. There were no significant differences in alpha diversity between protected and unprotected samples (Supplementary Figure 4).

The UPGMA cluster analysis separated the bacterial communities into two large clusters (SIMPROF, $P>0.01$ ) (Figure 3). One group contained all the samples from the wood center, whereas the other group contained samples from the wood surface. Within the surface cluster, all communities from the mesh-protected wood grouped together and were separated from the unprotected wood communities (Figure 3). Unprotected wood communities were more heterogeneous in their composition as shown by a loose clustering and longer branches in the dendrogram (Figure 3). Within the centre communities, there was no difference between the protected and unprotected samples.

The heatmap represented the distribution of 21 bacterial families from the wood surface and 17 from the wood centre (Figure 3). Sequences affiliated with the Vibrionaceae family dominated all of the wood centre samples $(60 \%$ of the sequences $\pm 20 \%, n=11$ ) and was dominant in only one unprotected sapwood surface sample (SSa_WoM_2). For surface samples, there were differences in the sequence abundance for the Bacteroidetes incertae sedi $(P=9.07 \mathrm{e}-4)$, Desulfovibrionaceae $\quad(P=3.16 \mathrm{e}-3), \quad$ Flavobacteriaceae $(P=0.024)$ and Rhodobacteraceae $(P=0.022)$. Desulfovibrionaceae and Bacteroidetes incertae sedi families were more abundant in the mesh-protected samples, whereas Flavobacteriaceae and Rhodobacteraceae were more abundant in the presence of Xylophaga spp. The Bacteroidetes incertae sedi members had low similarity to NCBI database sequences $(<97 \%)$. The Desulfovibrionaceae were all assigned to the Desulfovibrio. One-third of the Flavobacteriaceae were assigned to the Cellulophaga and $17 \%$ to the Psychroserpens genera ( $>97 \%$ similarity). One-third of the Rhodobacteraceae belonged to the Litoreibacter and $12 \%$ to the Sulfitobacter ( $>97 \%$ similarity) (Supplementary Figure 5).

Wood surface bacterial community composition For a more precise description of the wood surface community composition, we analysed the communities at the OTU level. A circular diagram shows the relationship between the ten most abundant OTUs and the different wood surface samples (Figure 4). The abundant OTUs ( $>1 \%$ of the sequences) represented $50 \%$ of the sequences in the wood without protection whereas they represented $70 \%$ of the sequences in the protected wood (Figure 4).

OTU 1 and 8 sequences were found mostly in the surface sapwood samples without mesh $(22.3 \%$ and $8.1 \%$, respectively). OTU 1 was identified as belonging to the Vibrionaceae family but was distantly related to any known bacterium sequences (best match in NCBI, EU540484: 94\%). OTU 8 was related to an uncultured Cellulophaga clone (97\% sequence similarity) found in northwest Spanish coastal sediments. 


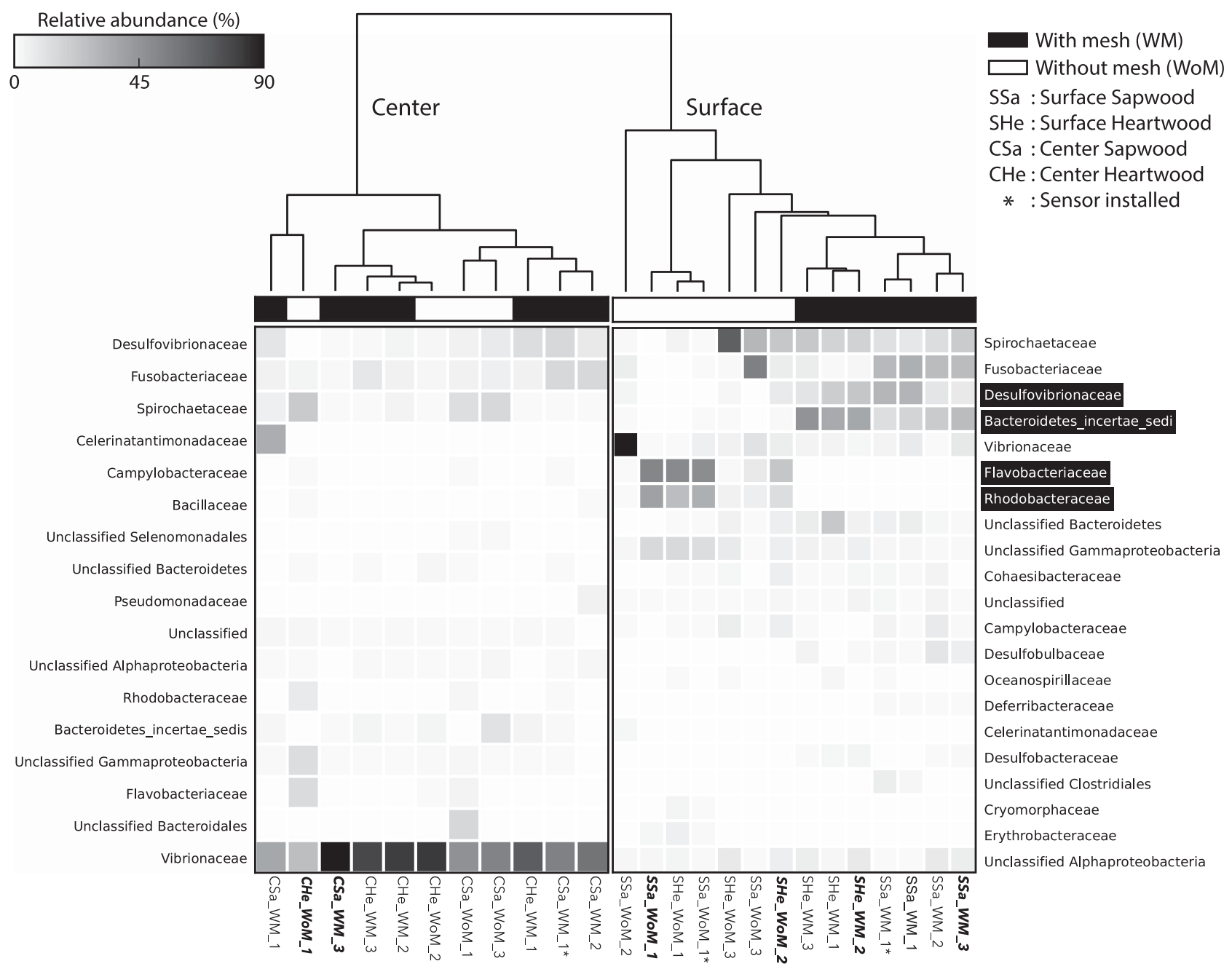

Figure 3 Bacterial community composition similarity between wood samples represented as a UPGMA cluster analysis based on the Bray-Curtis similarity index. Black cluster tips indicate protected samples, and white tips show unprotected samples. The heatmap represents the proportion of the most abundant bacterial families ( $>1 \%$ of the total number of sequences present in each of the two main clusters). Families marked in black showed a significant difference in relative sequence abundance (Welch $t$-test, $\alpha=0.05$ ) between protected and unprotected samples.

OTU 3 and 5 sequences were found mostly in wood surface that had been protected by the mesh $(17.1 \%$ and $11.3 \%$, respectively). Both OTU sequences belonged to the Desulfovibrio (95 and 99\% similarity, respectively). This genus is known to contain bacteria that can produce sulfide from sulfate (Kuever, 2014). OTU 3 was very closely related to a well-characterized Desulfovibrio that was isolated from deep-sea wood fall (Khelaifia et al., 2011). OTU 6 and 7 were also typical for mesh samples $(26.2 \%, 22.8 \%$ and belonged to the Bacteroidetes family, which is linked with high molecular weight polymer degradation rather than monomers (Cottrell and Kirchman, 2000; FernándezGómez et al., 2013).

OTU 2 and 4 were found in both protected and unprotected wood logs, OTU 2 was found more frequently in unprotected heartwood $(12.5 \%)$, and OTU 4 was found more frequently in sapwood with mesh $(24.2 \%)$. OTUs 2 and 4 presented low similarity to Spirochaetaceae (93\%) and Fusobacteriaceae sequences (92\%), respectively.

\section{Metagenome beta diversity}

Metagenome beta diversity was represented as an UPGMA dendrogram (Figure 5) constructed from the distance matrix calculated with the COMMET software (Maillet et al., 2014). The metagenomes separated in two main clusters. One contained the two unprotected surface samples that had been bored by Xylophaga spp. The second cluster contained two sub-clusters: one that grouped the two wood centre metagenomes and the other one with the two protected surface samples. The metagenome cluster analysis revealed a different pattern than the bacterial diversity analysis, which first discriminated the vertical position in the wood logs. 


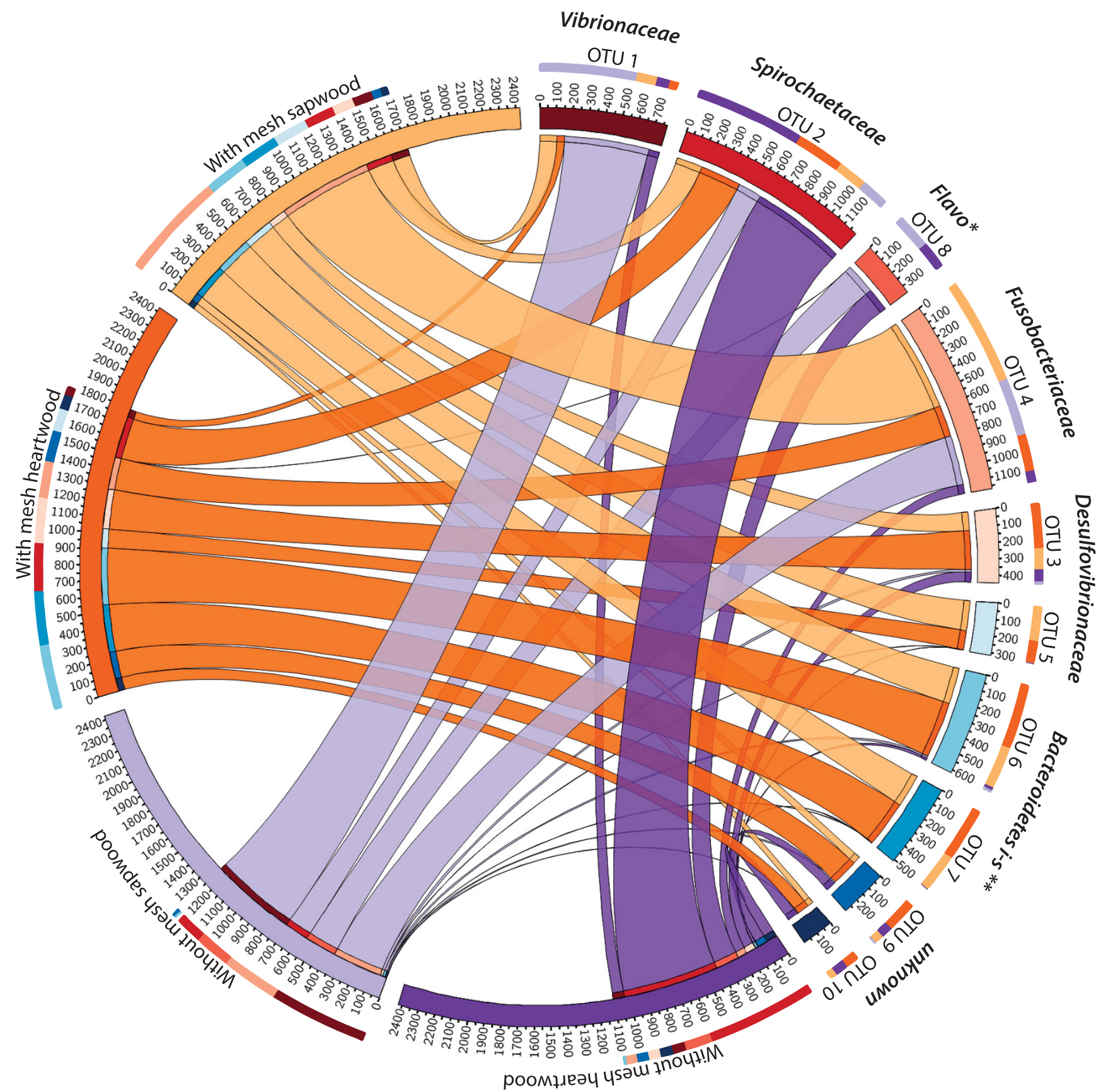

Flavo*: Flavobacteriaceae

Bacteroidetes $i$-s ${ }^{* *}$ : Bacteroidetes_incertae_sedis

Figure 4 Circular diagram showing the proportion of sequences of the ten most abundant OTUs in the different wood surface samples. The ribbon width represents the total number of sequences from an OTU that belong to a sample pool. Purple ribbons indicate an unprotected sample category, whereas orange ribbons show protected samples categories. Darker ribbons connect OTUs to heartwood samples, whereas lighter ribbons connect OTUs to sapwood samples. The bars below the OTU names indicate the contribution of each sample pool to these OTUs.

\section{Functional genes}

We focused on genes involved in metabolic pathways potentially present during wood degradation in the marine environment (Supplementary Table 2). The plots of gene abundance at the wood surface against abundance in the wood centre show first that the selected pathways are always present at the surface when they are detected in the wood centre
(Figure 6). Second, this comparison shows that when the wood is protected against borers, the relative abundance of many of the targeted functional genes decreased in the wood centre (Figure 6, Supplementary Figure 6c). This is true for genes related to sulfur oxidation that decreased from 62 occurrences to 0 , genes related to aerobic respiration that decreased from 1239 to 48 and genes related to 
the cellulosome that decreased from 18 to 0. Third, boring by Xylophaga spp. in the unprotected wood decreased the occurrence of fermentation related genes at the surface from 13836 occurrences in absence of wood borers to 2303 in their presence. This was also observed for genes related to dissimilatory sulfate reduction that decreased from 2292 occurrences to 261 occurrences and aerobic respiration from 4000 to 2240 occurrences in presence of Xylophaga spp. (Supplementary Figure 6a). Some metabolic pathways were not impacted by the presence of Xylophaga spp. like nitrate reductionrelated genes with 820 occurrences in the absence of borers and 915 occurrences when they were present.

\section{Discussion}

Our $520 \mathrm{~m}$ depth experiment revealed the ability of sunken wood microorganisms to produce hydrogen sulfide in the absence of Xylophaga spp. under natural deep-sea conditions. We thus demonstrate that microorganisms alone could produce a significant amount of reduced compounds essential for the chemolithotrophic growth of symbiotic or free-living microorganisms. This short-term exclusion experiment in a submarine canyon validates that microbial organic substrate degradation in seawater can lead to relatively high level of sulfide production in the absence of wood borers, consistent with the result of earlier experiments based on aquaria incubations (Yücel et al., 2013). Using shotgun metagenomics, we have located the community that have the genetic capacity to produce hydrogen sulfide within the first centimetre of wood rather than at the wood center even in the absence of wood borers. This finding contradicts the hypothesis that wood-boring bivalve colonization is the primary driver of the creation of anoxic niches available for bacteria to produce sulfide (Turner, 1973; Bienhold et al., 2013; Voight, 2015). In the early stage of immersion, bacteria appear to be the primary colonizers that may favour the subsequent settlement of macrofaunal species such as the wood-boring bivalves or chemosynthetic mussels.

The impact of Xylophaga spp. on the wood matrix was nevertheless very important. The bivalves had degraded ca. $30 \%$ of the wood after only 3 months of immersion, and no such degradation of the wood matrix was observed in the protected wood. The disruptive effect of Xylophaga spp. has been for long observed in the deep-sea. The first observations made from the Alvin in 1972 described sunken wood after 104 days of immersion as 'weakened and falling apart while touched by the submarine arm' (Turner, 1973). Experiments showed more recently that Xylophaga spp. are fast growing deep-sea organisms (Tyler et al., 2007; Ristova et al., 2017). Xylophaga spp. also grew quickly in our Western Mediterranean experiment, but, more interestingly, they significantly impacted the wood microorganism communities.

Surface microbial communities from Xylophaga spp. colonized wood logs were significantly different from communities of protected wood logs. In addition, sulfide accumulation in the wood was lower in the presence of Xylophaga spp., suggesting that bivalve colonization impacted microbial activity. Xylophaga spp. containing wood logs had more bacteria belonging to the Flavobacteriaceae and Rhodobacteriaceae families. Because members of the Rhodobacteriaceae family are aerobic, we hypothesize that through the boring activity of Xylophaga spp. oxygen is introduced into the wood. Xylophaga spp. inhale seawater with their inhalant siphon centimetres away from the wood surface burrow and then after breathing part of the oxygen exhale the partially oxygenated water close to their shell (Purchon, 1941; Voight, 2015). This partially oxygenated water brings other seawater electron acceptors (sulfate, nitrate), creating new redox gradients that can influence the microbial communities and enhance the recruitment of taxa with diverse energetic pathways. We observed an higher proportion of sequences related to Rhodobacteriaceae, Litoreibacter (OTU17) and Sulfitobacter (OTU32) that are both strictly aerobic (Sorokin, 1995; Romanenko et al., 2011), and Sulfitobacter, which is a potential chemolithotroph (five sulfitobacter genera out of the nine known to date) that is able to oxidize sulfide (Sorokin, 1995). These changes in the community composition occurred simultaneously with changes in the metabolic pathways present within the wood. The appearance of niches suitable for hydrogen sulfide consumers, suggested by the presence of Sulfitobacter and the higher proportion of sequences associated with the sulphur oxidizing SOX gene family, could explain the lower sulfide accumulations in Xylophagacolonized wood logs. However, the lower concentrations may also be due to lower production rate, as fewer potential sulfate-reducing taxa and fewer genes associated to sulfate reduction pathways were detected when the wood was tunnelled by woodboring bivalves.

The Flavobacteriaceae family contains aerobic bacteria (Bernardet and Nakagawa, 2006) that are capable of degrading a large variety of macromolecules (Reichenbach, 2006), from cellulose to fucoidan (Sakai et al., 2002). Among them, members of the Cellulophaga (OTU 8) may be strictly aerobic and able to use disaccharides such as cellulobiose but not cellulose (Pati et al., 2011). Some genes associated to the cellulosome, which is the protein complex responsible for cellulose degradation (Bégum and Lemaire, 1996), were present when Xylophaga spp. were boring the wood, but they were not detected when the wood was protected. We thus make the hypothesis that cellulose-degrading genes were either brought within the wood directly by the Xylophaga spp., who may harbour wood-digesting 


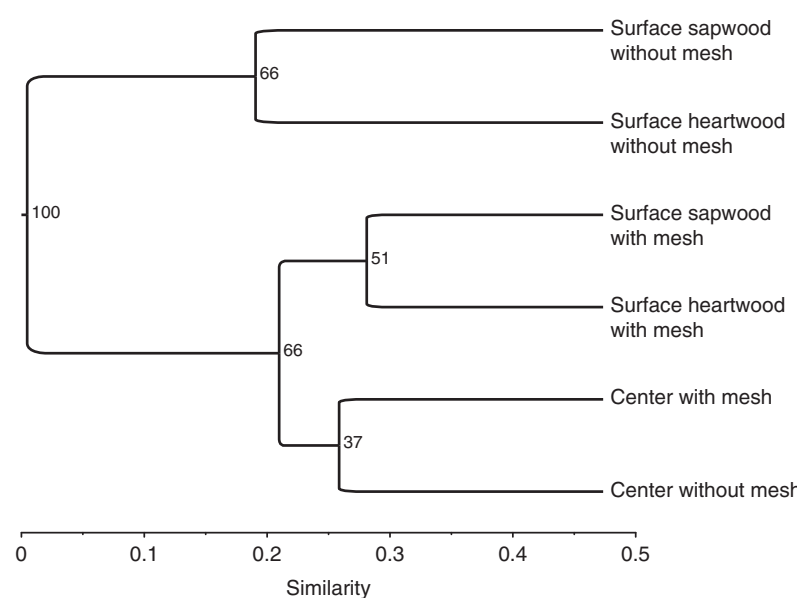

Figure 5 UPGMA dendrogram showing the similarity between metagenomes sampled from the protected and unprotected wood logs. Similarity is calculated from a direct non-assembled read comparison between metagenomes (see material and methods). Bootstrap values are shown at the nodes.

bacteria within their gut (Distel and Roberts, 1997), or indirectly, by increasing the bio-accessibility of the cellulosic material (Voight, 2015) and thus favouring the development of new ecological niches suitable for cellulose-degrading bacteria.

In the absence of Xylophaga spp., the wood is anoxic as suggested by the dominance of sequences from anaerobic or facultative anaerobic bacteria from the Bacteroidetes incertae sedi and Desulfovibrionaceae families. This corroborates previous aquaria experiments that showed wood became suboxic after only 2 days in seawater (Yücel et al., 2013). These earlier aquaria measurements also indicate that the possible absence of oxygen on the surface of the mesh-protected in situ wood logs was not due to a mesh-effect. Anoxia favours fermentative pathways inside the wood as indicated by the presence of OTUs that belong to the Marinifilum genus, which has been previously found in sunken wood (Fagervold et al., 2012; Ristova et al., 2017) and comprises facultative anaerobes that ferment sugars (Na et al., 2009). The presence of fermentation marker genes within the wood in both experimental conditions is also a strong indicator. Fermentation products such as acetate could then be used as a carbon source by organisms from the Desulfovibrionaceae family, which are able to reduce sulfate to hydrogen sulfide. The desulfovibrionaceae OTU 3 was very close to Desulfovibrio piezophilus previously found on sunken wood (Khelaifia et al., 2011; Kalenitchenko et al., 2015).

There were also significant differences in composition and diversity between communities from the surface and the centre of the wood, which is in accordance with results obtained earlier in an aquaria experiment (Kalenitchenko et al., 2015). In both protected and unprotected wood logs, the wood centre was not impacted by the Xylophaga spp. burrows. All centre samples were dominated by one

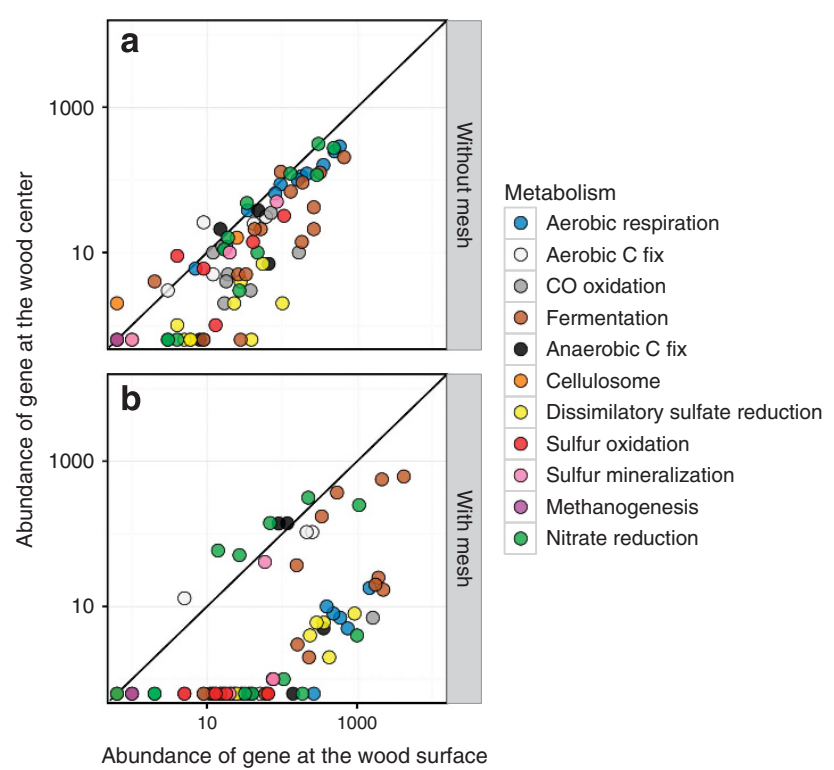

Figure 6 Abundance of genes in association with wood degradation metabolisms in seawater. The upper panel presents the results obtained when logs were not protected with a mesh, whereas the lower panel shows the results obtained for mesh-protected wood logs. Both panels compare the center metagenomes against the surface heartwood metagenomes.

single OTU identified as belonging to the Vibrionaceae family. Vibrionaceae have been detected in sunken wood after only 1 day of immersion (Bienhold et al., 2013) and are massively present in all of our samples collected after 2 months but not detected in the same range of dominance in older samples (Bienhold et al., 2013; Kalenitchenko et al., 2015; Ristova et al., 2017), which highlight the opportunistic lifestyle of this marine OTU.

Our data show that Xylophaga spp. wood-boring activity enhanced the diversification of metabolic pathways inside the wood and thus perturbed the early colonizing bacterial communities previously described ex situ (Kalenitchenko et al., 2016). If Xylophaga spp. were absent from the ecosystem because of disrupted larval connectivity (Glover et al., 2013) or because wood logs reach anoxic areas (Björdal, 2012), the early bacterial communities would be maintained, and wood degradation would rely on fermenting bacteria. Degradation will be slow and sulfide enrichment will be high resulting in long-persisting wood as illustrated by discoveries of marine archaeological wood logs (Sandström et al., 2002).

\section{Conclusion}

We demonstrated the capacity of the sunken wood microbial community to produce hydrogen sulfide, which is the base of the wood chemosynthetic ecosystem, in the absence of Xylophaga spp. in a natural deep-sea environment. The accumulation of hydrogen sulfide in the wood occurred in the absence of Xylophaga spp. The bivalves' burrows 
may allow seawater circulation, which creates aerobic niches suitable for sulfide-oxidizing bacteria. Deeper in the wood, away from the area affected by Xylophaga spp., our metagenomic data draw the picture of a fermenting environment that becomes more functionally diverse when Xylophaga spp. dug burrows.

\section{Conflict of Interest}

The authors declare no conflict of interest.

\section{Acknowledgements}

The present work was supported by the Agence Nationale de la Recherche (ANR) project MICADO (ANR-11)SV7Q23-003-01), the UPMC and Fondation TOTAL as part of the chair 'Extreme marine environments, Biodiversity, and Global change' and by the CNRS GDRE DIWOOD. We thank the crew of the R/V 'Minibex' (COMEX) for their assistance during fieldwork. We are grateful to Julie Rius and Benjamin Falgas from the 'Biodiversarium' in Banyuls sur Mer for their kind and precious help in providing pine wood and Yannick Banuls from the laboratory carpentry for precisely cutting the wood logs.

\section{References}

Bernardet J-F, Nakagawa Y. (2006). An Introduction to the Family Flavobacteriaceae. In: The Prokaryotes. Springer New York: New York, NY, pp 455-480.

Bernardino AF, Smith CR, Baco A, Altamira I, Sumida PYG. (2010). Macrofaunal succession in sediments around kelp and wood falls in the deep NE Pacific and community overlap with other reducing habitats. Deep-Sea Res Part I 57: 708-723.

Bessette S, Fagervold SK, Romano C, Martin D, Le Bris N, Galand PE. (2014). Diversity of bacterial communities on sunken woods in the Mediterranean Sea. J Mar Sci Technol 22: 60-66.

Bégum P, Lemaire M. (1996). The cellulosome: an exocellular, multiprotein complex specialized in cellulose degradation. Crit Rev Biochem Mol Biol 31: 201-236.

Bienhold C, Pop Ristova P, Wenzhöfer F, Dittmar T, Boetius A. (2013). How deep-sea wood falls sustain chemosynthetic life. Plos ONE 8: e53590.

Björdal CG. (2012). Microbial degradation of waterlogged archaeological wood. J Cult Herit 13: 1-5.

Bolger AM, Lohse M, Usadel B. (2014). Trimmomatic: a flexible trimmer for Illumina sequence data. Bioinformatics 30: 2114-2120.

Büttner M, Sauer N. (2000). Monosaccharide transporters in plants: structure, function and physiology. Biochem Biophys Acta 1465: 263-274.

Camacho C, Coulouris G, Avagyan V, Ma N, Papadopoulos J, Bealer K et al. (2009). BLAST+: architecture and applications. BMC Bioinformatics 10: 421.

Cottrell MT, Kirchman DL. (2000). Natural assemblages of marine proteobacteria and members of the Cytophaga-Flavobacter cluster consuming low- and high-molecular-weight dissolved organic matter. Appl Environ Microb 66: 1692-1697.

Cox MP, Peterson DA, Biggs PJ. (2010). SolexaQA: at-aglance quality assessment of Illumina secondgeneration sequencing data. BMC Bioinformatics 11: 485 .

Culliney JL, Turner RD. (1976). Larval development of the deep-water wood boring bivalve, Xylophaga atlantica Richards (Mollusca, Bivalvia, Pholadidae). Ophelia 15: 149-161.

Cuvelier D, Beesau J, Ivanenko VN, Zeppilli D, Sarradin P-M, Sarrazin J. (2014). First insights into macro- and meiofaunal colonisation patterns on paired wood/slate substrata at Atlantic deep-sea hydrothermal vents. Deep-Sea Res Part I 87: 70-81.

Dando PR, Southward AF, Southward EC. (1992). Shipwrecked tube worms. Nature 365: 667-667.

Deming JW, Reysenbach AL, Macko SA, Smith CR. (1997). Evidence for the microbial basis of a chemoautotrophic invertebrate community at a whale fall on the deep seafloor: Bone-colonizing bacteria and invertebrate Endosymbionts. Microsc Res Tech 37: 162-170.

Distel DL, Baco AR, Chuang E, Morrill W, Cavanaugh C, Smith CR. (2000). Do mussels take wooden steps to deep-sea vents? Nature 403: 725-726.

Distel DL, Roberts SJ. (1997). Bacterial Endosymbionts in the Gills of the Deep-Sea Wood-Boring Bivalves Xylophaga atlantica and Xylophaga washingtona. Biol Bull 192: 253.

Duperron S, Laurent MLCZ, Gaill FO, Gros O. (2008). Sulphur-oxidizing extracellular bacteria in the gills of Mytilidae associated with wood falls. FEMS Microbiol Ecol 63: 338-349.

Edgar RC, Haas BJ, Clemente JC, Quince C, Knight R. (2011). UCHIME improves sensitivity and speed of chimera detection. Bioinformatics 27: 2194-2200.

Fagervold SK, Bessette S, Romano C, Martín D, Plyuscheva M, Le Bris N et al. (2013). Microbial communities associated with the degradation of oak wood in the Blanes submarine canyon and its adjacent open slope (NW Mediterranean). Prog Oceanogr 118: 137-143.

Fagervold SK, Galand PE, Zbinden M, Gaill F, Lebaron P, Palacios C. (2012). Sunken woods on the ocean floor provide diverse specialized habitats for microorganisms. FEMS Microbiol Ecol 82: 616-628.

Fagervold SK, Romano C, Kalenitchenko, Borowski C, Nunes-Jorge A, Martin D et al. (2014). Microbial communities in sunken wood are structured by wood-boring bivalves and location in a submarine canyon. Plos ONE 9: e96248.

Fernández-Gómez B, Richter M, Schüler M, Pinhassi J, Acinas SG, González JM et al. (2013). Ecology of marine Bacteroidetes: a comparative genomics approach. ISME J 7: 1026-1037.

German CR, Von Damm KL. (2004). Hydrothermal processes. In: Elderfield H (ed), Treatise on geochemistry, vol 6. Elsevier: Oxford, UK, pp 181-222.

Gessner MO. (2005). Proximate lignin and cellulose. In: Graça MAS, Bärlocher F, Gessner MO (eds). Methods to Study Litter Decomposition. Springer Netherlands: Berlin/Heidelberg, pp 115-120.

Glover AG, Wiklund H, Taboada S, Avila C, Cristobo J, Smith CR et al. (2013). Bone-eating worms from the Antarctic: the contrasting fate of whale and wood remains on the Southern Ocean seafloor. Proc Roy Soc B 280: 20131390-20131390. 
Gomez-Alvarez V, Teal TK, Schmidt TM. (2009). Systematic artifacts in metagenomes from complex microbial communities. ISME J 3: 1314-1317.

Kalenitchenko D, Dupraz M, Le Bris N, Petetin C, Rose C, West NJ et al. (2016). Ecological succession leads to chemosynthesis in mats colonizing wood in sea water. ISME J 10: 2246-2258.

Kalenitchenko D, Fagervold SK, Pruski AM, Vétion G, Yücel M, Le Bris $\mathrm{N}$ et al. (2015). Temporal and spatial constraints on community assembly during microbial colonization of wood in seawater. ISME J 9: 2657-2670.

Kanehisa M, Goto S. (2000). KEGG: kyoto encyclopedia of genes and genomes. Nucleic Acids Res 28: 27-30.

Khelaifia S, Fardeau M-L, Pradel N, Aussignargues C, Garel M, Tamburini C et al. (2011). Desulfovibrio piezophilus sp. nov., a piezophilic, sulfate-reducing bacterium isolated from wood falls in the Mediterranean Sea. Int J Syst Evol Microbiol 61: 2706-2711.

Kiel S, Amano K, Hikida Y, Jenkins RG. (2009). Wood-fall associations from Late Cretaceous deep-water sediments of Hokkaido, Japan. Lethaia 42: 74-82.

Kozich JJ, Westcott SL, Baxter NT, Highlander SK, Schloss PD. (2013). Development of a dual-index sequencing strategy and curation pipeline for analyzing amplicon sequence data on the MiSeq Illumina sequencing platform. Appl Environ Microb 79: 5112-5120.

Krzywinski MI, Schein JE, Birol I, Connors J, Gascoyne R, Horsman D et al. (2009). Circos: An information aesthetic for comparative genomics. Genome Res 19: 1639-1645.

Kuever J. (2014). The family desulfovibrionaceae. In: Rosenberg E, DeLong E, Lory S, Stackebrandt E, Thompson F (eds). The Prokaryotes. Springer Berlin Heidelberg: Berlin, Heidelberg, pp 107-133.

Laurent MCZ, Gros O, Brulport J-P, Gaill F, Le Bris N. (2009). Sunken wood habitat for thiotrophic symbiosis in mangrove swamps. Mar Environ Res 67: 83-88.

Laurent MCZ, Le Bris N, Gaill F, Gros O. (2013). Dynamics of wood fall colonization in relation to sulfide concentration in a mangrove swamp. Mar Environ Res 87-88: 85-95.

Lemoine R, La Camera S, Atanassova R, Dédaldéchamp F, Allario T, Pourtau N et al. (2013). Source-to-sink transport of sugar and regulation by environmental factors. Front Plant Sci 4: 272.

Leschine SB. (1995). Cellulose degradation in anaerobic environments. Annu Rev Microbiol 49: 399-426.

Levin LA. (2005). Ecology of cold seep sediments: Interactions of fauna with flow, chemistry and microbes. In: Gibson RN, Gordon JDM, Atkinson RJA (eds). Vol. 43. Oceanography and Marine Biology: An Annual Review, Vol 43. CRC Press: Boca Raton, pp 1-46.

Ljungdahl LG, Eriksson K-E. (1985). Ecology of microbial cellulose degradation. Vol. 8. Advances in Microbial Ecology. Springer US: Boston, MA, pp 237-299.

Lorion J, Duperron S, Gros O, Cruaud C, Samadi S. (2009). Several deep-sea mussels and their associated symbionts are able to live both on wood and on whale falls. Proc Roy Soc B 276: 177-185.

Maillet N, Collet G, Vannier T. (2014), COMMET: comparing and combining multiple metagenomic datasets. 2014 IEEE International Conference on Bioinformatics and Biomedicine (BIBM) 94-98.

Meyer F, Paarmann D, D'Souza M, Olson R, Glass EM, Kubal M et al. (2008). The metagenomics RAST server a public resource for the automatic phylogenetic and functional analysis of metagenomes. BMC Bioinformatics 9: 386.

Mullineaux LS, Le Bris N, Mills SW, Henri P, Bayer SR, Secrist RG et al. (2012). Detecting the influence of initial pioneers on succession at deep-sea vents. Plos ONE 7: e50015.

Na H, Kim S, Moon EY, Chun J. (2009). Marinifilum fragile gen. nov., sp. nov., isolated from tidal flat sediment. Int J Syst Evol Microbiol 59: 2241-2246.

Overbeek R, Begley T, Butler RM, Choudhuri JV, Chuang $\mathrm{H}-\mathrm{Y}$, Cohoon M et al. (2005). The subsystems approach to genome annotation and its use in the project to annotate 1000 genomes. Nucleic Acids Res 33: 5691-5702.

Palacios C, Zbinden M, Pailleret M, Gaill F, Lebaron P. (2009). Highly similar prokaryotic communities of sunken wood at shallow and deep-sea sites across the oceans. Microb Ecol 58: 737-752.

Parks DH, Tyson GW, Hugenholtz P, Beiko RG. (2014). STAMP: statistical analysis of taxonomic and functional profiles. Bioinformatics 30: 3123-3124.

Pati A, Abt B, Teshima H, Nolan M, Lapidus A, Lucas S et al. (2011). Complete genome sequence of Cellulophaga lytica type strain (LIM-21 T). Stand Genomic Sci 4: 221-232.

Pruesse E, Quast C, Knittel K, Fuchs BM, Ludwig W, Peplies J et al. (2007). SILVA: a comprehensive online resource for quality checked and aligned ribosomal RNA sequence data compatible with ARB. Nucleic Acids Res 35: 7188-7196.

Purchon RD. (1941). On the Biology and Relationships of the Lamellibranch Xylophaga Dorsalis (Turton). J Mar Biol Assoc UK 25: 1-39.

Quast C, Pruesse E, Yilmaz P, Gerken J, Schweer T, Yarza P et al. (2013). The SILVA ribosomal RNA gene database project: improved data processing and webbased tools. Nucleic Acids Res 41: D590-D596.

Reichenbach H. (2006). The Order Cytophagales. In: The Prokaryotes. Springer New York: New York, NY, pp 549-590.

Reid SJ, Abratt VR. (2005). Sucrose utilisation in bacteria: genetic organisation and regulation. Appl Microbiol Biotechnol 67: 312-321.

Rho M, Tang H, Ye Y. (2010). FragGeneScan: predicting genes in short and error-prone reads. Nucleic Acids Res 38: e191-e191.

Ristova PP, Bienhold C, Wenzhöfer F, Rossel PE, Boetius A. (2017). Temporal and spatial variations of bacterial and faunal communities associated with deep-sea wood faalls. PLos One 12: e0169906.

Romanenko LA, Tanaka N, Frolova GM, Svetashev VI, Mikhailov VV. (2011). Litoreibacter albidus gen. nov., sp. nov. and Litoreibacter janthinus sp. nov., members of the class Alphaproteobacteria isolated from the seashore. Int J Syst Evol Microbiol 61: 148-154.

Romano C, Voight JR, Pérez-Portela R, Martin D. (2014). Morphological and genetic diversity of the woodboring Xylophaga (Mollusca, Bivalvia): new species and records from deep-sea Iberian canyons. PLos One 9: e102887.

Sakai T, Kimura H, Kato I. (2002). A marine strain of flavobacteriaceae utilizes brown seaweed fucoidan. Mar Biotechnol 4: 399-405.

Sandström M, Jalilehvand F, Persson I, Gelius U, Frank P, Hall-Roth I. (2002). Deterioration of the seventeenthcentury warship Vasa by internal formation of sulphuric acid. Nature 415: 893-897. 
Schloss PD, Westcott SL, Ryabin T, Hall JR, Hartmann M, Hollister EB et al. (2009). Introducing mothur: opensource, platform-independent, community-supported software for describing and comparing microbial communities. Appl Environ Microb 75: 7537-7541.

Shapiro RS, Spangler E. (2009). Bacterial fossil record in whale-falls: petrographic evidence of microbial sulfate reduction. Palaeogeography 274: 196-203.

Smith CR, Baco AR. (2003). Ecology of whale falls at the deep-sea floor. Oceanography Mar Biol 41: 311-354.

Sorokin DY. (1995). Sulfitobacter pontiacus gen. nov., sp. nov.-a new heterotrophic bacterium from the black sea, specialized on sulfite oxidation. Microbiology 64: 295-305.

Tatusov RL, Koonin EV, Lipman DJ. (1997). A genomic perspective on protein families. Science 278: 631-637.

Teske A, Alm E, Regan JM, Toze S, Rittmann BE, Stahl DA. (1994). Evolutionary relationships among ammoniaand nitrite-oxidizing bacteria. $J$ Bacteriol 176: $6623-6630$.

Treude T, Smith CR, Wenzhöfer F, Carney E, Bernardino AF, Hannides AK et al. (2009). Biogeochemistry of a deep-sea whale fall: sulfate reduction, sulfide efflux and methanogenesis. Mar Ecol Prog Ser 382: 1-21.
Turner RD. (1973). Wood-boring bivalves, opportunistic species in the deep sea. Science 180: 1377-1379.

Tyler PA, Young CM, Dove F. (2007). Settlement, growth and reproduction in the deep-sea wood-boring bivalve mollusc Xylophaga depalmai. Mar Ecol Prog Ser 343: 151-159.

Vergin KL, Urbach E, Stein JL, DeLong EF, Lanoil BD, Giovannoni SJ. (1998). Screening of a fosmid library of marine environmental genomic DNA fragments reveals four clones related to members of the order Planctomycetales. Appl Environ Microb 64: 3075-3078.

Voight JR. (2015). Xylotrophic bivalves: aspects of their biology and the impacts of humans. J Moll Stud $\mathbf{8 1}$ : 175-186.

Wilke A, Harrison T, Wilkening J, Field D, Glass EM, Kyrpides $\mathrm{N}$ et al. (2012). The M5nr: a novel nonredundant database containing protein sequences and annotations from multiple sources and associated tools. BMC Bioinformatics 13: 141.

Yoshioka PM. (2008). Misidentification of the Bray-Curtis similarity index. Mar Ecol Prog Ser 368: 309-310.

Yücel M, Galand PE, Fagervold SK, Contreira-Pereira L, Le Bris N. (2013). Sulfide production and consumption in degrading wood in the marine environment. Chemosphere 90: 403-409.

Supplementary Information accompanies this paper on The ISME Journal website (http://www.nature.com/ismej) 